\title{
Countermeasures Against Job Burnout Among College and University Administrators from the Perspective of Psychological Contract Theory
}

\author{
Qingguo Meng1*, Xiaojing Liu² \\ ${ }^{1}$ School of Management, Xuzhou Medical University, Xuzhou 221004, Jiangsu Province, China \\ ${ }^{2}$ Emergency Medicine Ward, The Affiliated Hospital of Xuzhou Medical University, Xuzhou 221006, Jiangsu Province, \\ China \\ *Corresponding author: Qingguo Meng, mqgxyd2019@163.com \\ Copyright: () 2022 Author(s). This is an open-access article distributed under the terms of the Creative Commons Attribution License (CC \\ BY 4.0), permitting distribution and reproduction in any medium, provided the original work is cited.

\begin{abstract}
Administrators are the implementers of the management in colleges and universities; however, their job scopes are relatively boring and complicated, with heavy workload and high work pressure, causing some of them to be less active and slack off in their careers. Therefore, under the guidance of psychological contract theory, colleges and universities should adopt various measures to deal with job burnout among college and university administrators. In this paper, the main causes of job burnout among college and university administrators are analyzed, and specific countermeasures are proposed from the perspective of psychological contract theory, hoping to help college and university administrators improve their work enthusiasm.
\end{abstract}

Keywords: Psychological contract theory; Colleges and universities; Administrators; Job burnout

Online publication: January 12, 2022

\section{Introduction}

The effective work development of college and university administrators directly affects the smooth progress of various activities in colleges and universities. However, due to the cumbersome work of administrators, they are prone to work fatigue; in addition, they are paid minimal wages, resulting in a certain psychological gap, which easily leads to job burnout. In turn, this would affect the smooth development of the management in colleges and universities. Therefore, it is urgent to deal with the job burnout of college and university administrators from the perspective of psychological contract theory.

\section{Main causes of job burnout among college and university administrators}

\subsection{Tedious work leading to mental fatigue}

The job responsibilities of college and university administrators are relatively broad, and their work targets do not only include the majority of students, but also the overall faculty and staffs, with highly repetitive job scope ${ }^{[1-3]}$, thus requiring a higher degree of care and patience from them. In addition, college and university administrators also need to be responsible for handling various emergencies; hence, they need to be prepared at all times, thus leaving their frame of minds in a constant state of tension. Therefore, college and university administrators tend to experience mental fatigue, which leads to job burnout ${ }^{[5-7]}$. 


\subsection{Low salary}

There is a huge difference between the responsibilities of college and university administrators and those of teachers, but the salary of many college and university administrators is lower than that of teachers; in addition, there are fewer opportunities for administrators in scientific research. Even if college and university administrators have put in a lot of effort in their work, they might not receive high scores or leadership recognition upon evaluation, thus leading to a tendency to experience job burnout as they mistakenly believe that no matter how much work is done, the result is the same ${ }^{[8]}$.

\section{Countermeasures against job burnout among college and university administrators from the perspective of psychological contract theory}

\subsection{Actively introduce flexible management mechanisms}

At this stage, most colleges and universities in China are implementing standardized, rigid, and institutionalized management mechanisms as well as paying more attention to the constraints and norms of the thoughts and behaviors of the managed subjects, in order to promote the development of ideological and moral consciousness, values, and behavioral habits that are in line with the management requirements [9-11]. However, in such a management mechanism, it is difficult to fully reflect the humanistic spirit of colleges and universities along with the concept of people-oriented management. From the perspective of psychological contract theory, if colleges and universities wish to solve the issue of job burnout, they need to actively break the previous management mechanism and design a flexible management mechanism, which does not mandatory restrict the behavior of administrators, but rather psychologically mobilize the enthusiasm and initiative of each administrator, focusing on the stimulation of their inner potential and the cultivation of a creative spirit, so as to achieve better management effect. In this way, work norms can be transformed into the spontaneous behavior of administrators, so as to promote strong internal drive and self-restraint. When managing administrators in colleges and universities, it is essential to highlight their emotional characteristics, promptly resolve their doubts and depressed moods, relieve their psychological pressure, and reduce the chance of job burnout ${ }^{[12,13]}$.

\subsection{Pay attention to the career development of administrators}

From the perspective of psychological contract theory, if colleges and universities wish to reduce the occurrence of job burnout, they have to recognize that the content of psychological contract is not fixed but needs to be reconstructed according to the actual situation of administrators. There is a huge difference between psychological contract and labor contract. Psychological contract has a dynamic characteristic. From the recruitment of administrators to their participation in the management of colleges and universities, the content of the psychological contract changes accordingly. When an administrator takes on a job, the content of the psychological contract will tend to the administrator's career development expectations. Therefore, in order to reduce the occurrence of job burnout, it is necessary to pay attention to the career development of administrators ${ }^{[14-18]}$. The career development cycle of administrators can be divided into eight notable periods: pre-employment period, initial period of employment, skill building period, professional enthusiasm growth period, setback period, stable period, fade period, and leaving period. The knowledge system, professional skills, emotional attitude, professional rest, professional experience, and work mentality of administrators vary during different periods. Colleges and universities need to have a correct view on the career development cycle of administrators and then provide care and guidance based on the period of their current career development. In addition to regular training and learning, it is also important to strengthen the emotional communication with administrators to effectively solve the issue of job burnout ${ }^{[19]}$. 


\subsection{Design reasonable incentive mechanisms}

Incentive mechanism is used to stimulate people through various ways and methods, so as to motivate them to work ${ }^{[20]}$. For college and university administrators, their characteristics, values, psychological needs, and work styles are different. Previous motivational theories have already played a role in motivating modern administrators. Psychological contract theory can provide a new way for colleges and universities to motivate them. College and university administrators pay more attention to their own working environment, business achievements, career development, and salary. Therefore, in the process of designing an incentive mechanism, colleges and universities should introduce achievement incentives, honor incentives, model incentives, goal incentives, performance incentives, etc. under the guidance of psychological contract theory. At the same time, colleges and universities should also introduce environmental incentives and salary incentives to create good office environment and office equipment for administrators while increasing their salaries. In this way, it promotes a sense of balance between labor and salary, thus positively stirring their mood for work and preventing job burnout.

\section{Conclusion}

In conclusion, the responsibilities of college and university administrators are complex, and their workload is heavy; therefore, it is not rare to find them being in a burnout state. The introduction of psychological contract theory can help colleges and universities solve this issue. Under the guidance of this theory, colleges and universities should actively introduce flexible management mechanisms, pay attention to the career development of administrators, and design a reasonable incentive mechanism to encourage them to be more active in their work.

\section{Disclosure statement}

The authors declare that there is no conflict of interest.

\section{References}

[1] Li Y, Zhu C, 2019, Research on the Influencing Factors and Intervention Strategies of Selected Students' Job Burnout from the Perspective of Psychological Contract. Study Forum, 000(006): 54-62.

[2] Dang Y, Wei X, 2020, Discuss the Solution to the Job Burnout of Young Teachers in Colleges and Universities Based on the Maintenance of Psychological Contract. Modern Education Forum, 3(8): 12-13.

[3] Rong Q, 2019, A Study on the Relationship Between Psychological Contract, Job Satisfaction, and Job Burnout of Physical Education Teachers in Elementary and Middle Schools, Shanghai Normal University.

[4] Song Y, 2019, Research on the Relationship Among College Teachers' Psychological Contract, Job Satisfaction, and Job Burnout. Advances in Psychology, 009(001): 91-97.

[5] Liu B, 2020, An Empirical Analysis of Teachers' Psychological Contract, Job Satisfaction and Job Burnout in Independent Colleges - Taking the Five Independent Colleges of Gongqing "Science and Education City" as Examples. Journal of Higher Education, 2020(28): 11-14.

[6] Zhang Z, 2019, Research on the Management of Teachers in Higher Vocational Colleges from the Perspective of Psychological Contract Theory - Taking Yancheng Higher Vocational Colleges as an Example. Human Resources Development, 2019(18): 28-29. 
[7] Li Y, Jiang Q, 2020, Research on Organizational Intervention Strategies of University Managers' Job Burnout. Educational Theory and Practice, 2020(9): 17-18.

[8] Du H, 2020, Investigation and Cause Analysis of the Current Situation of College Counselors' Job Burnout from the Perspective of Public Management. Friends of Humanities, 000(004): 108.

[9] Liu M, 2019, Research on Job Burnout of Teaching Secretaries in Higher Vocational Colleges. World of Labor and Social Security, 525(05): 42.

[10] Liu D, 2019, Research on the Influencing Factors of Job Burnout of Administrative Staff in Colleges and Universities, Xiangtan University.

[11] Liu S, 2020, Research on the Causes and Countermeasures of Job Burnout of University Managers. Yangtze River Technology and Economy, 2020(S1): 109-110.

[12] Xu R, 2019, Research on Job Burnout and Countermeasures of Basic-level Administrative Staff in Colleges and Universities, Nanjing University of Technology.

[13] Dong C, 2019, Research on Employee Turnover from the Perspective of Psychological Contract, Shandong Jianzhu University.

[14] Guan J, 2020, The Impact of Job Burnout on the Professional Identity of Hospital Administrators. China Health \& Nutrition, 30(12): 333.

[15] Ding N, 2019, How to Overcome Job Burnout in the Administrative Management of Higher Vocational Colleges. Contemporary Educational Practice and Teaching Research, 2019(6): 86-87.

[16] Tang W, 2020, The Phenomenon of Job Burnout of Educational Administrators in Private Higher Vocational Colleges: An Analysis Based on the Three Dimensions of Macro, Meso and Micro. Science and Technology Wind, 2020(14): 116.

[17] Sun X, 2020, Research on Job Burnout and Countermeasures of Administrative Staff in Colleges and Universities. Farm Staff, 2020(06): 258-259.

[18] Zhang L, Shu Y, Huang Y, 2019, Research on the Job Burnout of University Teaching Administrators in Shanghai and Countermeasures. Education Modernization, 2019(59): 120-121, 125.

[19] Guo J, 2019, Research on the Job Burnout of Administrative Staff Under the Goal Management System. Journal of Taiyuan City Vocational and Technical College, 000(007): 42-44.

[20] Zhao Y, 2019, Analysis on the Job Burnout of Teaching Managers in Colleges and Universities in the New Era. Curriculum Education Research, 2019(20): 209-210.

Publisher's note

Bio-Byword Scientific Publishing remains neutral with regard to jurisdictional claims in published maps and institutional affiliations. 